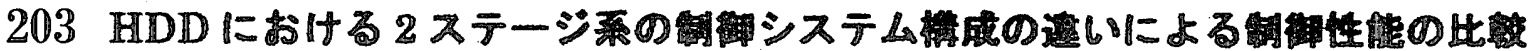

\section{Comparison of Feedback controllers for a Dual-Stage Hard Disk Drive}

\author{
○学 松井 通(忮阜大学)
}

\author{
正 佐々木 実（岐阜大学）
}

\author{
Tohru MATSUI, Gifu University, Yanagido1-1, Gifu-shi, Gifu \\ Minoru SASAKI, Gifu University
}

\begin{abstract}
This paper discusses four track-following controller designs for a dual stage hard disk drive system with a slider based piezoelectric micro:actuator. The use of dual stage actuator in hard disk drive system has become a means of achieving increased servo actuator bandwidth. LQG regulator is applied to the compensator design of a dual stage hard disk drive. This paper is described and compared four control system architectures (Parallel loop, Master-Slave, Master-Slave with De-coupling, Dual feedback) for a dual stage hard disk drive system. Numerical simulations in both frequency and time domains show performance improvements of the dual stage hard disk drive system over the conventional single stage hard disk drive system.
\end{abstract}

Key Words: Dual Stage HDD, LQG regulator, Control system architectures, Parallel loop, MasterSlave, Dual feedback, Master-Slave with De-coupling

\section{1. はட゚゙た}

磁気ディスク装置の大容量化，高性能化に対応するためには，

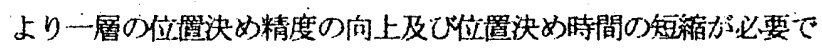
ある.しかし，磁気ディスク装固には，位置决め性能，追従性能 に悪影揰を与える様々な外乱が存在する。それらを抑班するには、 高精度位置決ぬ機構を実現し，制御系のサ一ボ帯域を抎大するこ とぶ有効であり，また，高周波数域まて感度関数を小さくするこ とが有効である. しかし, 従来のボイスコイルモータ(VCM)のみ で位置决めを行うシングルステージ系では，これらの仕様を満た すのは限界があり，困難であると思狆る，そこで，本研究におう いては, マイクロアクチュエータ(MA)を微動アクチュエータと し、VCM を粗動アクチュエータとした 2 ステージアクセスサー ボ機搆系を構成し，状热量を推定してなおおつ外乱を考虑に入れ て外乱推性性を高め，さらに Following 制御評価関数を用いて 最適化することのできる LQG 制御理論を適用して，4 種類の 2 ステージ系の制御システム構成を取り上げ、制御性能について比 較・検討する.

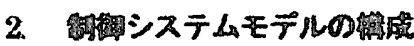

高速・高精度な位㯰決め制御を実現するために，平行型 (Parallel loop), マスタースレーブ型(Master-Slave loop), デュ アルフィードバック型(Dual feedhack locp), 非干涉マスタースレ 一ブ型(价ter-Slave with De-coupling)の 4 種頪の制御システムそ デルを構築し，それらの特性について示与。

平行型は，Fig1に示dようにVCM 上マイクロアクチュエータ 亚並列に接続し，各々の出力の和を目標位置にフィードバックす
るものである. この場合の閉ルーブ后達関数と感度関数は(1)，(2) 式のようになる.

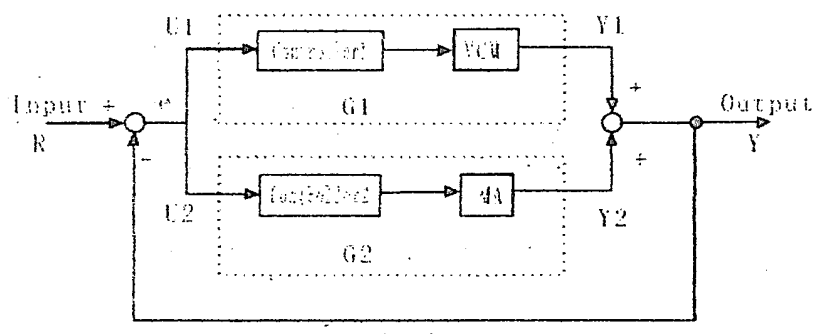

Fig 1 Paralled Loop Controd System

$$
\begin{aligned}
& G(s)=\frac{Y(s)}{R(s)}=\frac{G_{1}+G_{2}(s)}{1+G_{1}(s)+G_{2}(s)} \\
& G_{\text {sensitiviy }}(s)=\frac{e(s)}{R(s)}=\frac{1}{1+G_{1}(s)+G_{2}(s)}
\end{aligned}
$$

マスタースレイブ型は, マイクロアクチュエータが目標に追従 し、VCM は, マイクロアクチュエータが動作の限界を超えない ように追従するもので, そのモデル図を Fg.2 に示す：また， こ の場合の閉ループ伝達関数と感度関数は(3)，(4)式のようになる. 


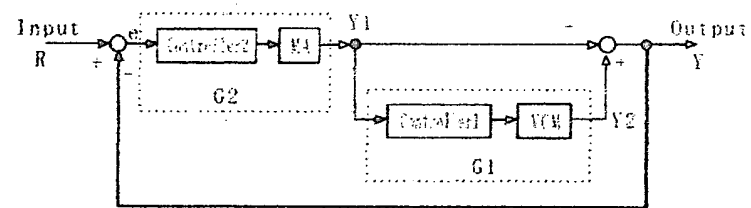

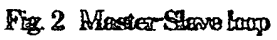

$G(s)=\frac{Y(s)}{R(s)}=\frac{G_{2}+G_{1}(s) \cdot G_{2}(s)}{1+G_{2}(s)+G_{1}(s) \cdot G_{2}(s)}$

$G_{\text {sensitivis }}(s)=\frac{e(s)}{R(s)}=\frac{1}{1+G_{2}(s)+G_{1}(s) \cdot G_{2}(s)}$

デュアルフィードバック型は、VCM が目標値に追従する一方， その偏差をマイクロアクチュエータによって儎正させるものであ る. そのモデル図を Fig3 に示す. また，二の埸合の閉ループ伝 達関数と感度閔数は(5)，(6)式のようになる。

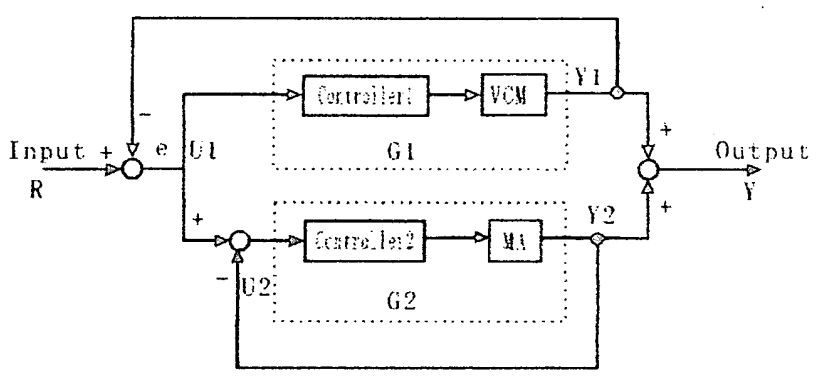

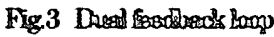

$G(s)=\frac{Y(s)}{R(s)}=\frac{G_{1}+G_{2}+G_{1}(s) \cdot G_{2}(s)}{1+G_{1}+G_{2}(s)+G_{1}(s) \cdot G_{2}(s)}$

$G_{\text {senstiving }}(s)=\frac{e(s)}{R(s)}=\frac{1}{\left\{1+G_{1}(s)\right\}\left\{1+G_{2}(s)\right\}}$

非干涉マスタースレーブ型は, マスタースレーブ型にフィード フォワードが付け加えられたもので, これによって, 完全に切り 雖して VCM とマイクロアクチュエータのコントラーラを設部で きる. そのモデル图を Fig4 に示す，また，この場合の閉ループ 伝達関数と感度関数は(7), (8)式のようになる.

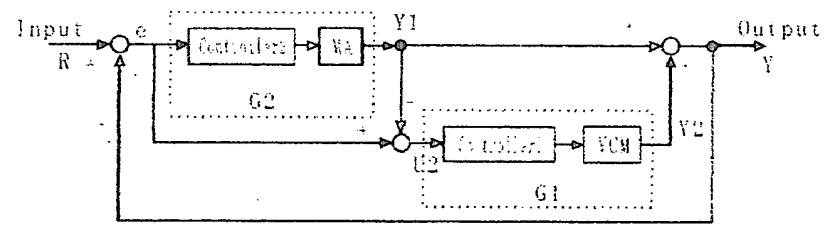

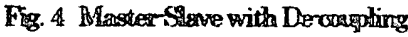

$$
\begin{aligned}
& G(s)=\frac{Y(s)}{R(s)}=\frac{G_{1}+G_{2}+G_{1}(s) \cdot G_{2}(s)}{1+G_{\mathrm{i}}+G_{2}(s)+G_{1}(s) \cdot G_{2}(s)} \\
& G_{\text {sensitviig }}(s)=\frac{e(s)}{R(s)}=\frac{1}{\left\{1+G_{1}(s)\right\}\left\{1+G_{2}(s)\right\}}
\end{aligned}
$$

\section{LOG 制御理緢}

LOG 制御問題は白色性ノイズを含む以下の制御システム

$$
\begin{aligned}
& \dot{x}=A x+B u+\xi \\
& y=C x+D u+\eta
\end{aligned}
$$

に対して，次の評価関数を最小にするような最適入力を求める問 題である. ただし，yは出力，乡およびクは白色性ノイズであ る. 白色性ノイズとは，ノイズとしてあらゆる周波数成分を含む 不規則信号で，どの周波数に対してもそのパワーがお㧍よそ一定 の大きさを示すノイズのことである.

$J=E\left[\lim _{T \rightarrow \infty} \frac{1}{T} \int_{0}^{T}\left\{x(t)^{T} Q x(t)+u(t)^{T} R u(t)\right\} d t\right]$

LAG 制御問題を解くためには，以下の LAG 制御問題の仮定が成 り立たなければならない。

A 1 ： $(A, B)$ 可安定 (通常は可制御)

A $2: R>0$

A 3 : $Q \geq 0,\left(Q^{1 / 2}, A\right) \quad$ 可検出

A4: $(C, A)$ 可検出（通常は可観測）

また，LQG制御問題は，状態フィードバックとオブザーバゲ インは別々に設計可能であるという分離定理により，LQ制御問 題と Kalman フィルタ問題に分けることができ，LQ制御問題の 解が

$$
u=-F x
$$

と与えられ，また，カルマンフィルタ閣題が

$$
\hat{\dot{x}}=A \hat{x}+B u-H(y-C \hat{x})
$$


と与えられるとき，これらより LQG 制御問題で求まる制御器は

$$
K(s)=F(s I+A+B F+H C)^{-1} H
$$

となる.

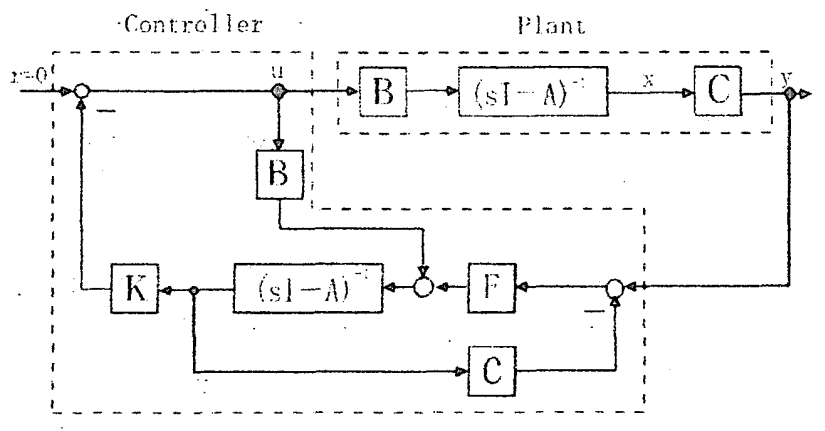

Fig. 5 LQG Control System

\section{4. 数傎シミュレーション結果}

第 2 世代型マイクロアクチュエータについ, LQG 制御理論を 適用し，ディジタルコントローラを設計し，4種類の 2 ステージ 采制御システム構成の制御性能について比較・検討する．Fig 6 に数值シミュレーションに用いた第2 世代型マイクロアクチュエ 一タの構成を示寸.

今回使用した VCM とマイクロアクチェエータは, Fgg7, Fig8 に示すような周波数特性のものを使用した。

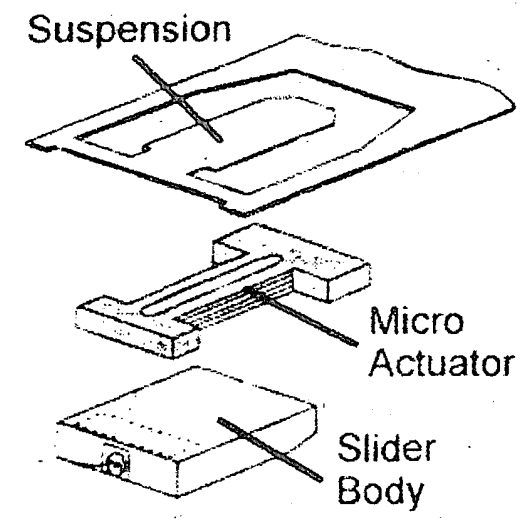

Fig. 6 Architecture of Micro Actuator
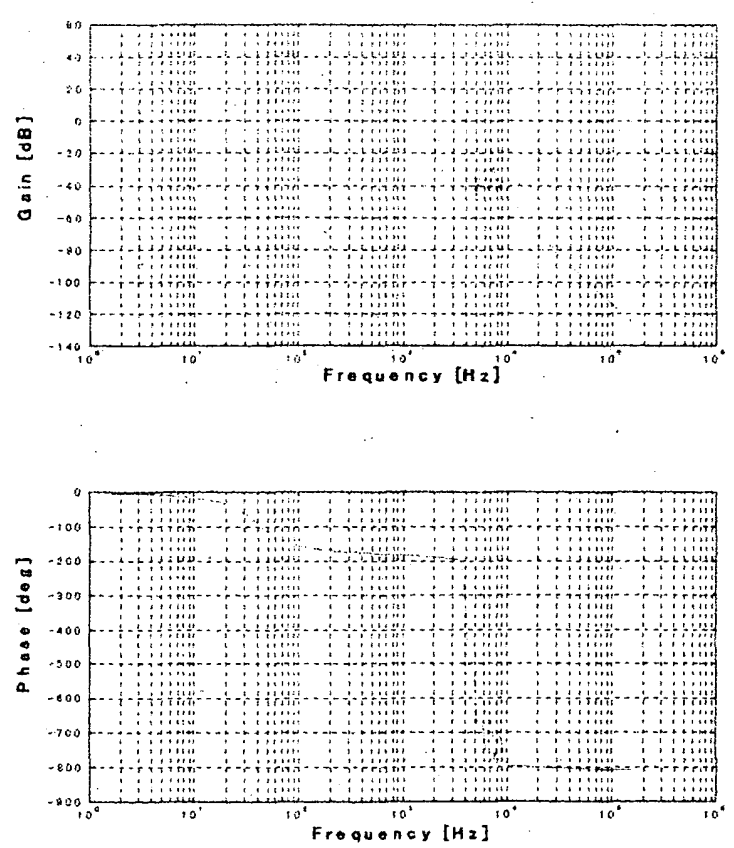

Fig. 7 Bode diagram of VCM
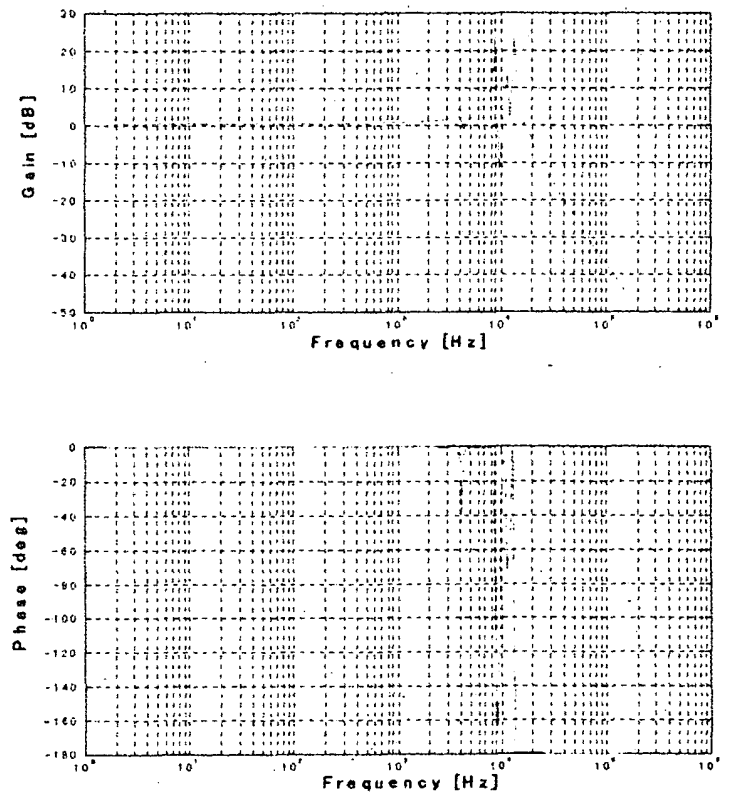

Fig. 8 Bode diagram of Micro Actuator

各制御モデルについて LQG 制御理論をもちいて制御系を設計 し, 数值シミュレーションを行った. ディジタルコントローラの サンプリング周期は $10[\mu \mathrm{sed}$ である.

平行型についての閉ループ周波数特性を Fig9 に示寸。サーボ

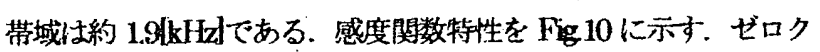
ロス周波数は $9.2[\mathrm{kHz}$ ，低周波数域におけすダインは $59.8 \mathrm{ddB]}$

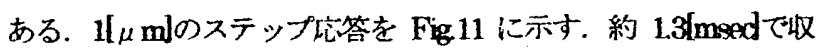
束している事が分かる. 

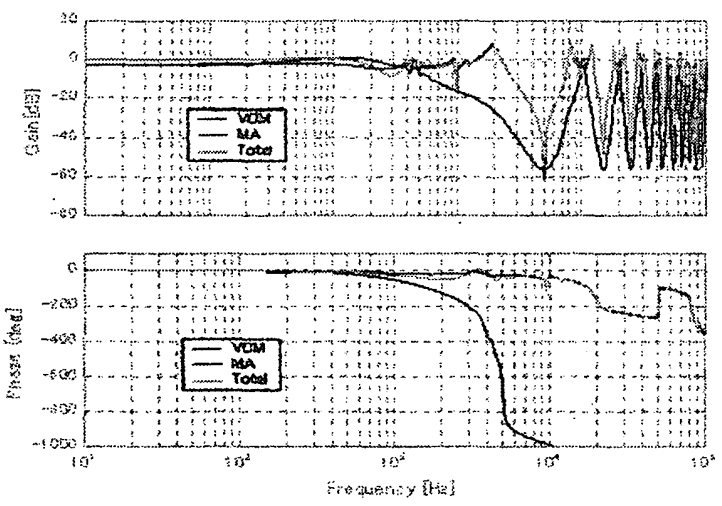

Fig.9 Bode diagram of Parallel bop system
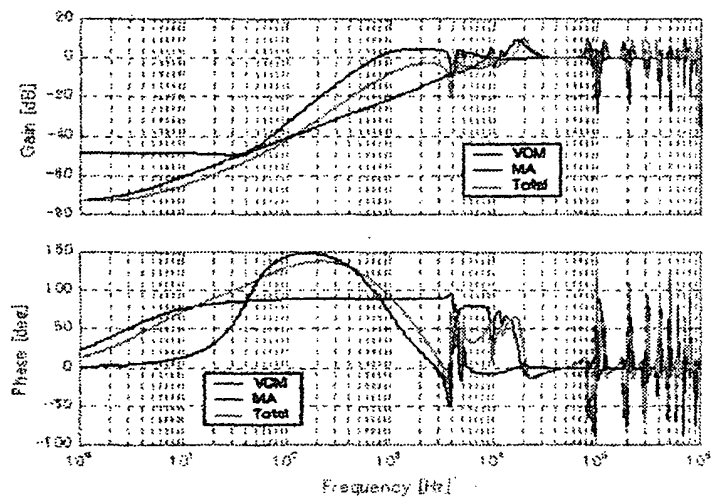

Fig 10 Bode diagram of Paralkel lonp sensitivity function

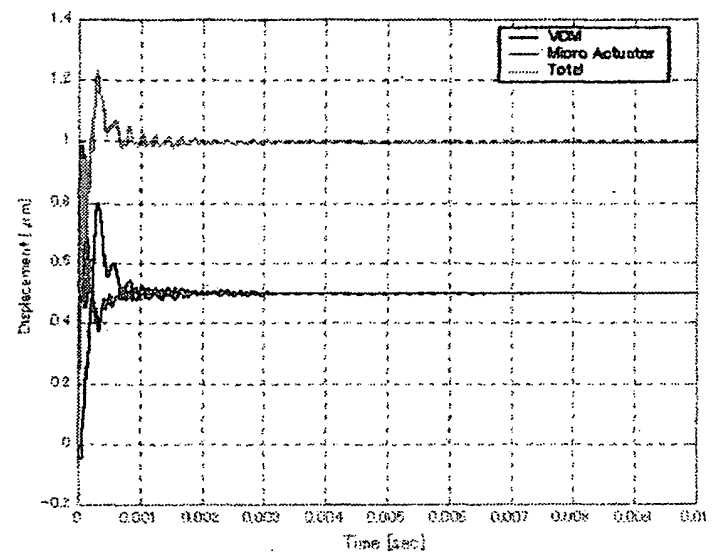

Fig.11 Step response of Parallel loop system

マスタースレーブ型についての閉ループ周波数特性を F 12 に

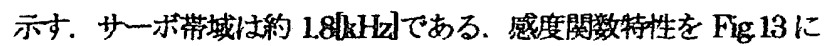
示す. ゼロクロス周波数は $9.2 \mathrm{kH} 2$ ，低周波数域におけるグイン

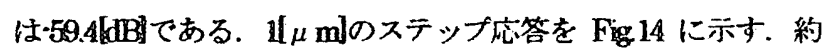
$1.3 \mathrm{msed}$ で収束している事が分かる。
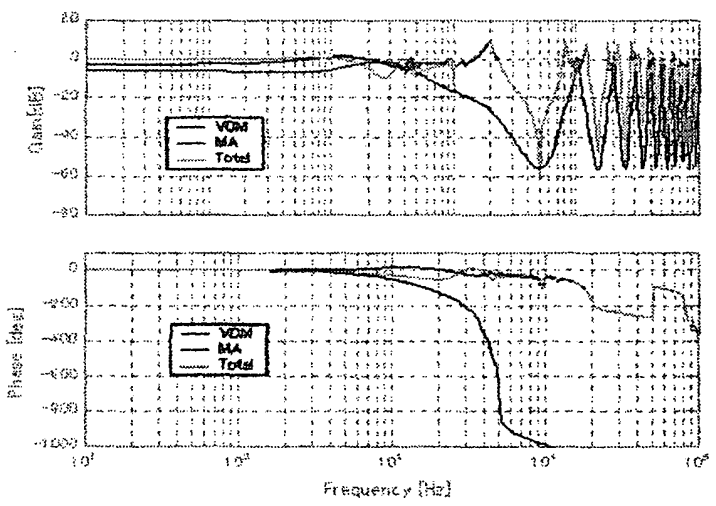

Fig 12 Bade diagram of MasterSlave loop system
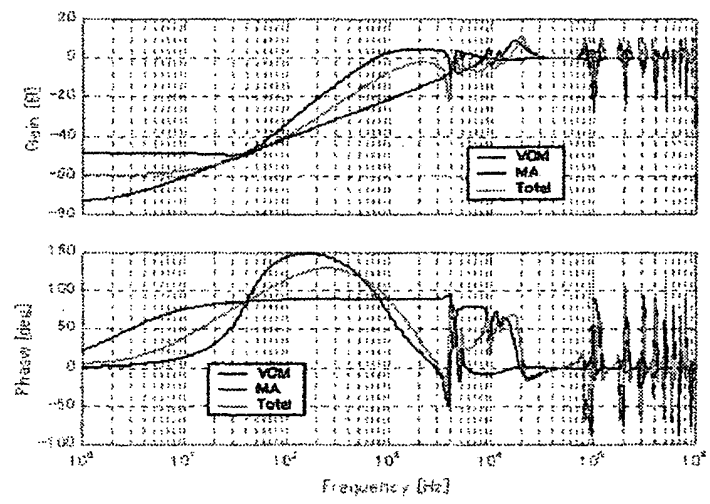

Fig. 13 Bode diagram of Master Slave hop sensitivity function

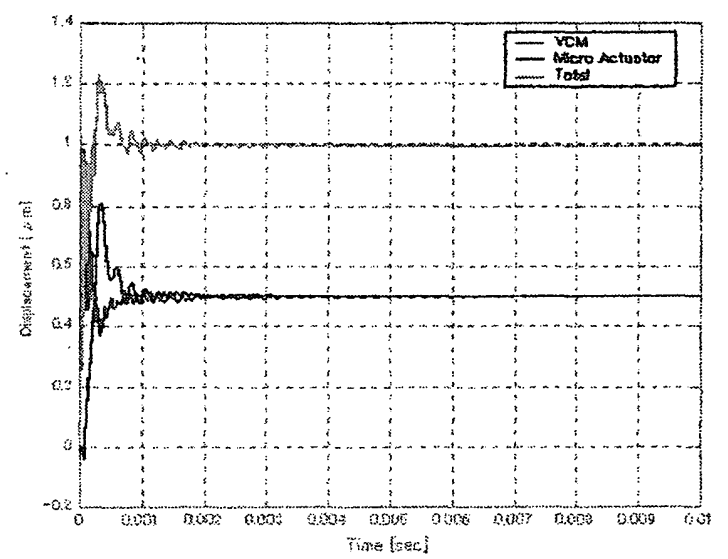

Fig.14 Step response of Master-Slave boup system

デュアルフィードバック型についての閉ループ周波数特性を

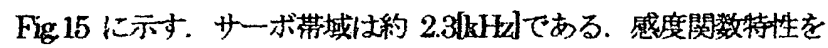

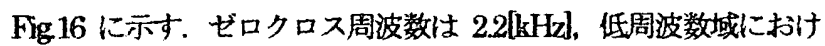

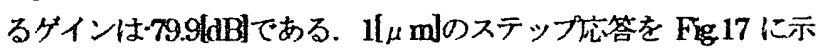
寸. 䄪 $1.8[\mathrm{msed}]$ て収束している事が分かる. 

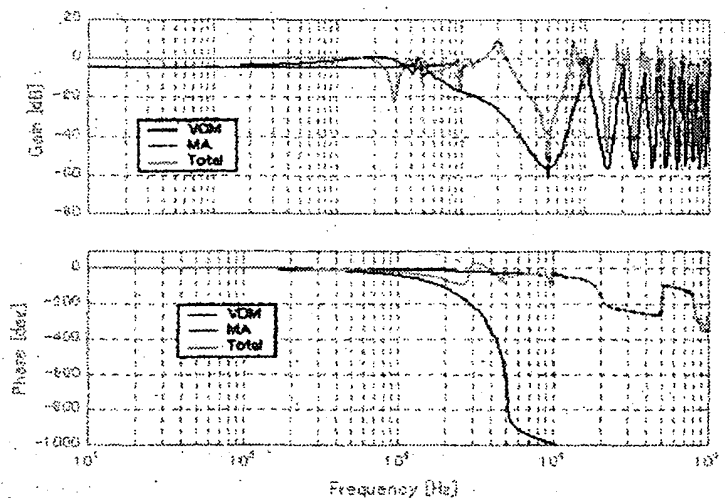

Fig.15 Borle diagram of Dual feedback loop system

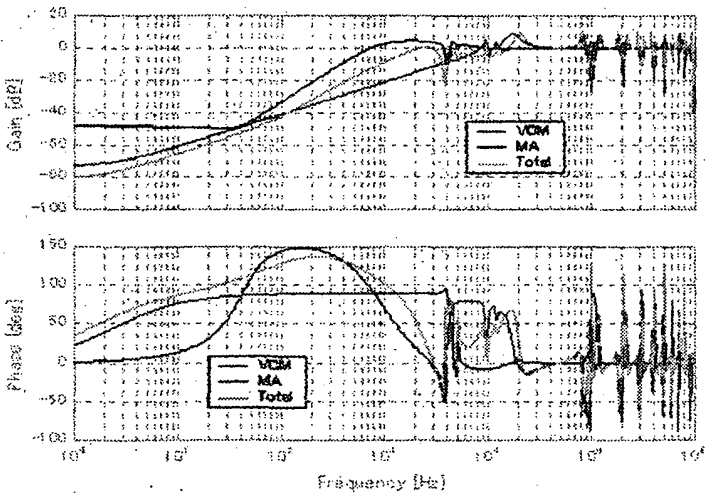

Fig.16 Bode diagram of Dual feedhack locp sensitivity function

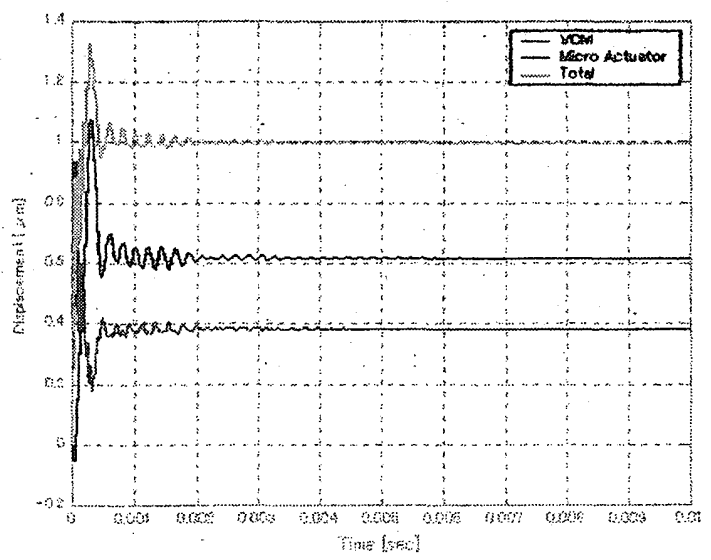

Fig.17 Step response of Dual feedhack loop system

非干涉マスタースレーフ型についての閉ループ周波数特性を Fig.18に示す。サーボ帯城は䄪 2.5[kHz〕である. 感度関数特性を

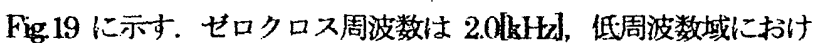
るゲインは72.2[dB]である. $1[\mu \mathrm{ml}$ のステッナ応答を Fig.20に示 す. 約 $2.01 \mathrm{msed}$ で収束している事が分かる.
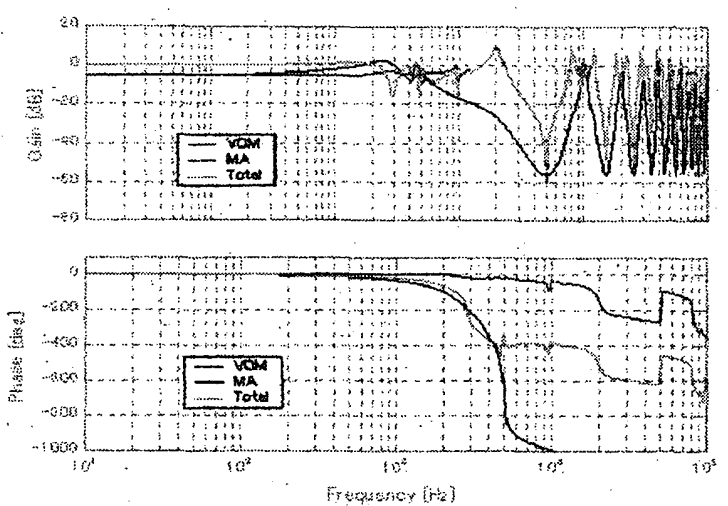

Fig.18 Bode diagram of Master-Slave with De-coupling system
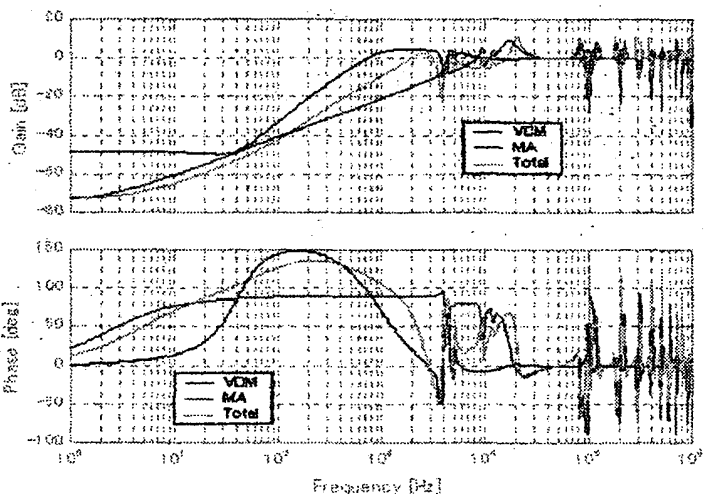

Fig.19 Bode diagram of Master-Slave with De-coupling sensitivity function

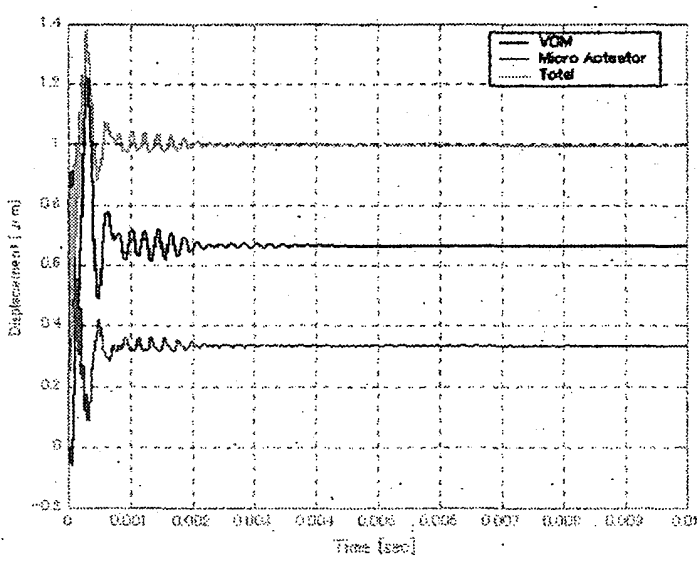

Fig.20) Step response of Master-Slave with De-coupling system

4 種類の 2 ステージ制御系搆成とシングルステージの閉ループ 周波数特性, 感度特性, ステップ忘答の結果を比較した表を Table 1 に示す 
Tabte 1 Control performanne

\begin{tabular}{|c|c|c|c|c|c|c|c|}
\hline & \multicolumn{2}{|c|}{ Closed loop system } & \multicolumn{3}{|c|}{ Sensutivity function } & \multicolumn{2}{|c|}{ Step respanse } \\
\hline & $\begin{array}{l}\text { Servo } \\
\text { Bandwidth }\end{array}$ & Peat gain & $\begin{array}{l}\text { Low- } \\
\text { Frequency } \\
\text { gain }\end{array}$ & $\begin{array}{l}\text { Frequency } \\
\text { at } 0[\mathrm{~dB}]\end{array}$ & Peak Eain & $\begin{array}{l}\text { Over } \\
\text { shoot }\end{array}$ & $\begin{array}{l}\text { Setting } \\
\text { time }\end{array}$ \\
\hline $\begin{array}{l}\text { Tarallel } \\
\text { oop }\end{array}$ & $1.9[\mathrm{kHz}]$ & $7.5[48]$ & $-59.8[68]$ & $0.2[\mathrm{kHz}]$ & $10.0[\mathrm{~dB}]$ & $0.23[\mu \mathrm{m}]$ & $1.3[\mathrm{msec}]$ \\
\hline $\begin{array}{l}\text { Staster- } \\
\text { Slave }\end{array}$ & $1.8[\mathrm{tH}+\mathrm{tz}]$ & $0.0[\mathrm{~dB}]$ & $-50.4[\mathrm{~dB}]$ & $0.2[\mathrm{hHz}]$ & $11,3[48]$ & $0.23[\mu \mathrm{m}]$ & $1.3[\mathrm{msec}]$ \\
\hline $\begin{array}{l}\text { Dual } \\
\text { feedback } \\
\text { jooge }\end{array}$ & $2.3[\mathrm{kHz}]$ & $8.4[\mathrm{~dB}]$ & $-79.9[\mathrm{~dB}]$ & $2.2[\mathrm{kHz}]$ & $10.8[\mathrm{AB}]$ & $0.32[\mu \mathrm{m}]$ & $1.8[\mathrm{msec}]$ \\
\hline $\begin{array}{l}\text { Master- } \\
\text { Slave } \\
\text { oprith De. }\end{array}$ & $2.5[\mathrm{kHz}]$ & $8.0[08]$ & $-72.2[\mathrm{~dB}]$ & 2.0[12Hz] & $11.2[\mathrm{~dB}]$ & $0.38[\mu \mathrm{m}]$ & $2.0[\mathrm{msec}]$ \\
\hline Singe & $23[\mathrm{x}+\mathrm{kz}]$ & $3.5[\mathrm{~dB}]$ & $-48.6[\mathrm{~dB}]$ & 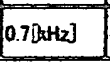 & $4.6[\mathrm{~dB}]$ & $0.38[\mu \mathrm{m}]$ & $2.8[\mathrm{msec}]$ \\
\hline
\end{tabular}

Table 2 Gain Margin and Phase Margin

\begin{tabular}{|c|c|c|}
\hline & Gain Margin & Phase Margin \\
\hline Parallel loop & $3.2[\mathrm{~dB}]$ & $29.6[\mathrm{deg}]$ \\
\hline Master-Slave loop & $2.5[\mathrm{~dB}]$ & $29.1[\mathrm{deg}]$ \\
\hline Dual feedback loop & $18.1[\mathrm{~dB}]$ & $78.1[\mathrm{deg}]$ \\
\hline $\begin{array}{c}\text { Aaster-Slave } \\
\text { ith De-coupling }\end{array}$ & $18.1[\mathrm{~dB}]$ & $78.1[\mathrm{deg}]$ \\
\hline \begin{tabular}{c} 
Single Stage \\
\hline
\end{tabular} & \begin{tabular}{c} 
DidB] \\
\hline
\end{tabular} & $56.2[\mathrm{deg}]$ \\
\hline
\end{tabular}

まと的

4 種類の 2 ステージ系の制御システム構成を取り上げ、これら のシステム榡成の違いりよる制御性能を比䡈するために，各制御 系について数值シミュレーションを行った.

闒ループ周波数特性においては，ピークゲインの抑圧は平行型 か゚最も厦れているが、サ一ボ带域を見ると, 非干涉マスタースレ 一フ型が他のモデルに比べて高いサーボ帯域を実現できることが 分かった．感度特性においては，ぜロクロス周波数忙非干涉マス タースレーブ型, ディアルフィードバック型が他に比へて低く， 速応性はかなり劣る. 低周波数域のゲインは，非干涉マスタース レーブ型, テュアルフィードバック型は低く抑えられている. ス テップ答においては，平行型，マスタースレーブ型がオーバー シュートが抑えられ，整定時間も短く，目標位置に素早く収束し， 速応性に䌿れている. これらのことを総合すると，他の墈成に比 較して平行型が良好な制敏特性を示しているものと思われる。

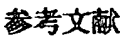

[1] Fan, L.S., Ottesen H. H, Reiley, T. C. and Wood, R. W.; "Magnetic Reconting Head Positioning at Very High Track Densities Using a Microactuator Based Tworstage Servo System," IEEE Thans, on Magnetica, No.42-3, pp.222-233, 1995.
[2] Koganzzawa, S., Takaishi, K., Mizoshita, Y., Uematsu Y., Yamada, T., Y., Yamada, T., Hasegawa, S. and Uemo, T.; “A Flexural Piggyback Mini-Artuzator for over 5 Gibit/in² Density Magnetic Recording" IEEE Trans on Magnetics, No.32-5, pp.3908-3910, 1996.

[3] J.Y. Yen, K Hallamasek, and R Horwwitz, "Tradk-Following Controller Design for a Compound Disk Drive Actuator," ASME Joumal of Dynamic Systems, Measurement, and Control, Vol.112, pp.391·402, 1990.

[4] T. Suzaki, M. Sasaki, F. Füisawa, T. Usui, T. Yoshida and H. Hirai, "Rabust'Track Following Control of Dual Stage Hard Disk Drive using Mixed Sensitivity Problem," Prac af the 2nd Asian Contral Conference, Seoul, Korea, July 22-25, pp. III-2239. 242, 1997.

[5] T. Surauki, T. Usui, M. Sasaki, F. Fujisawa, T. Yoshida, and H. Hirai, "Comparison of Robust Track-Following Control Systems for a Dual Stage Hand Dsk Drive”, Adv. Infa Storage Syst., Vol. 10, pp.101-118, 1999.

[6] T. Suzuki, K Satoh M. Sasaki, F. Fujisawa, K Mori and O. Haruaki, "Robust Tracking Following Control of Dual Stage. Hand Disk Drive," Thind International Conference on Motion and Vibration Control, pp.142-147, 1996.

[7] T.Mori, H. Munemoto, Y. Otsuki, and K. Akagi "A DuratStage Magnetic Disk Drive Actuator using a Piezcolectric Devioe for a High Track Density," IEEEE Trans, on Mragnetics, Vol27, No.6, pp.5298-5300, 1991.

[8] K Ito, T. Mirura and M. Sasaki. ; Track-Following Control of Dual Stage Hard Disk Drive," Promerlings of 3rd IWAM, pp.93-98, December, 1999.

[9] Y. Soeno, S. Ichikawa, T. Tsuna, T. Sato, and I. Sato, "Piezoelectric Piggy-Back Microactuator fur Hard Disk Drive," IEEE Trans on Magneticas Vol.35, №.2, pp.983-987, 1999.

[10] Lin, Guo., Doughas, Martin and Don, Brunnet; "Dual-stage Actuator servo Control for High Density Disk Drives", Proc of International Conference on Advanced Intelligent. Mechatronics, pp.132-137, 1989. 